\title{
COOPERAÇÃO TÉCNICA DA ESCOLA DE ENFERMAGEM DE RIBEIRÃO PRETO DA UNIVERSIDADE DE SÃO PAULO NA FORMAÇÃO DE PROFISSIONAIS DE ENFERMAGEM PARA A REPÚBLICA POPULAR DE ANGOLA*
}

\author{
Neide Fávero ** \\ Maria Cecília Morais Scatena ** \\ Dulce Maria Silva Vendrúsculo **
}

\section{INTRODUÇÃO}

Sendo a Escola de Enfermagem de Ribeirão Preto da Universidade de São Paulo (EERP-USP), um Centro Colaborador da OPAS/OMS e frente a necessidade de formação de recursos humanos na área de enfermagem da República de Angola, foi firmado em novembro de 1991, um convênio de cooperação internacional entre a Universidade de São Paulo e Ministério da Saúde da República Popular de Angola.

No âmbito deste convênio foram assinados dois termos de acordo mútuo:

a) termo de acordo mútuo entre EERP-USP e o Departamento de Formação Técnico Profissional (DFTP) do Ministério da Saúde da República Popular de Angola (MINSA) para intercâmbio acadêmico e estudantil ao nível de graduação e posteriormente pós-graduação e material bibliográfico.

* Trabalho apresentado no $1^{\circ}$ Encontro Internacional de países de língua Oficial Portuguesa - Salvador - BA Brasil

** Professor Doutor da Escola de Enfermagem de Ri beirão Preto da Universidade de São Paulo 
Este acordo objetivava a formação de enfermeiros e o preparo destes para assumirem a organização do curso de graduação em enfermagem e a função de docência no ensino da enfermagem em seu país, assim como capacitá-los para a direção de escolas de enfermagem de nível técnico.

Para tanto, este convênio previa o envio sistemático de 5 (cinco) estudantes a cada ano letivo, perfazendo um total de 20 (vinte) alunos.

A seleção dos estudantes era de responsabilidade do DFTP-MINSA. Os gastos com passagens e manutenção dos estudantes no Brasil ficaram a cargo do MINSA e ASDI (Agência Sueca para Desenvolvimento Internacional).

Em contrapartida, a Escola de Enfermagem de Ribeirão Preto-USP se comprometeu receber anualmente 5 estudantes angolanos no curso de graduação em Enfermagem e oferecer formação em nível de licenciatura a todos os estudantes enviados pelo DFTP MINSA.

Até 1993, enquanto o curso de licenciatura desta unidade estava em processo de criação os estudantes puderam obter esta formação em outra escola da região - UNESP*** Araraquara.

Os alunos convênio tiveram um acompanhamento semestral de seu desempenho acadêmico com elaboração de relatórios para o DFTP-MINSA.

Coube ainda a esta unidade a sistematização. anual de cursos e/ou programas extracurriculares de acordo com as necessidades observadas e/ou interesse dos estudantes.

Tendo em vista as funções que iriam assumir em seu país de origem, estes alunos nos últimos semestres do curso, participaram junto aos docentes das áreas Enfermagem Materno-Infantil, Enfermagem de Saúde Pública e Enfermagem Fundamental da programação e execução das disciplinas do curso de graduação, bem como de programas de reciclagem oferecidos ao pessoal de enfermagem da rede básica de saúde.

b) termo de acordo mútuo entre a Escola de Enfermagem de Ribeirão Preto-USP e Instituto Superior de Enfermagem do Ministério da Saúde da República Popular de Angola para intercâmbio de docentes e técnicos de saúde para o ensino e organização acadêmica; intercâmbio de material bibliográfico e assessoria docente nas áreas: Enfermagem Fundamental, Enfermagem Saúde Coletiva, Enfermagem Saúde do Trabalhador, Enfermagem Saúde da Mulher e da Criança, Pedagogia Aplicada à Enfermagem e Gestão Aplicada à Enfermagem, além de assessoria para assuntos relacionados à investigação.

Neste sentido, foi elaborado um programa com cronograma de visitas de docentes da Escola de Enfermagem de Ribeirão Preto - USP a Angola.

Esta parte do acordo até o momento não foi contemplada devido às condições políticas e econômicas decorrentes da guerra civil de Angola.

*** UNESP - Universidade Estadual de São Paulo 
Diante da temática proposta para nossa participação no I Encontro na oficina de cooperação técnica para formação de Profissionais de Enfermagem Graduação e Nível Médio, iremos nos deter ao programa de formação de estudantes de graduação de Angola.

\section{PERFIL E DESEMPENHO ACADÊMICO DO ESTUDANTE CONVÊNIO}

Embora este convênio tenha sido oficializado em 1991, esta unidade já vinha, desde 1989 mantendo contatos com representantes de Angola com a finalidade de fixar os termos do convênio em curso. Os primeiros alunos angolanos para o curso de graduação em Enfermagem vieram através do Programa Estudante Convênio (PEC) em 1988.

O quadro 1 mostra a distribuição dos alunos conforme ano de matrícula.

Os estudantes foram selecionados em seu país de origem, como já foi mencionado anteriormente. Segundo informações dos próprios alunos, nos dois primeiros anos (88 e 89) a seleção foi feita considerando o conhecimento e a área de atuação do candidato, bem como o aspecto político partidário; uma vez que, na época era importante a formação de pessoas que não trairiam os ideais revolucionários de Angola.

Acreditamos que este fato repercutiu diretamente no desempenho escolar de alguns alunos como veremos posteriormente.

A partir de 1990 o critério de seleção dos alunos mudou priorizando o conhecimento através de provas, assim como trabalhar na área da saúde. Certificamos que esta medida repercutiu diretamente no desempenho escolar de alguns alunos como veremos posteriormente.

QUADRO 1 - DISTRIBUIÇÃO DOS ALUNOS ANGOLANOS CONFORME ANO DE MATRÍCULA

\begin{tabular}{|c|c|}
\hline ANO & $\mathbf{N}^{\circ}$ de alunos ingressantes \\
\hline 1988 & 03 \\
1989 & 03 \\
1990 & 04 \\
1991 & 05 \\
1992 & $--^{\star}$ \\
1993 & $06^{\star \star}$ \\
\hline Total & $\mathbf{2 1}$ \\
\hline
\end{tabular}

* Não foram enviados alunos devido ao recrudescimento da guerra civil.

** Em 1993 foram matriculados 6 novos alunos devido a desistência de um estudante matriculado em 1991. 
No que diz respeito ao perfil destes alunos, através do Quadro 2, percebe-se que a maior parte dos estudantes convênio (16) apresentavam mais de 31 anos no momento de ingresso no Curso de Graduação em Enfermagem, enquanto que a maioria dos demais alunos desta unidade iniciam o curso numa faixa etária entre 18 e 22 anos.

QUADRO 2 - PERFIL DO ESTUDANTE ANGOLANO DE ACORDO COM A FAIXA ETÁRIA, SEXO E ESTADO CIVIL, NO MOMENTO DE INGRESSO NO CURSO DE GRADUAÇÃO EM ENFERMAGEM

\begin{tabular}{|c|c|c|c|c|c|c|}
\hline \multirow{2}{*}{$\begin{array}{c}\text { Faixa } \\
\text { etária }\end{array}$} & \multicolumn{2}{|c|}{ Masculino } & \multirow{2}{*}{ Total } & \multicolumn{2}{c|}{ Feminino } & \multirow{2}{*}{ Total } \\
\cline { 2 - 3 } \cline { 6 - 7 } & Casado & Solteiro & & Casada & Solteira & \\
\hline 22 a 25 & - & 2 & 2 & - & - & - \\
\hline 26 a 30 & - & 2 & 2 & - & 1 & 1 \\
\hline 31 a 36 & 4 & 2 & 6 & - & 2 & 2 \\
\hline 36 a 43 & - & 2 & 2 & 3 & 3 & 6 \\
\hline Total & $\mathbf{4}$ & $\mathbf{8}$ & $\mathbf{1 2}$ & $\mathbf{3}$ & $\mathbf{6}$ & $\mathbf{9}$ \\
\hline
\end{tabular}

Embora a enfermagem em nosso país seja uma profissão eminentemente feminina, no grupo de alunos angolanos (12) prevaleceu o sexo masculino.

Talvez este.dado possa ser explicado pelo fato de ser mais fácil para os homens saírem de seu país, uma vez que culturalmente cabe às mulheres cuidar dos filhos e da família.

Quanto ao estado civil, ainda que conste que a maioria dos estudantes angolanos é solteira, alguns referiram ter cônjuge e filhos no país de origem o que era motivo de preocupação para eles, refletindo as vezes, no desempenho escolar.

Em relação ao tempo gasto por estes alunos para conclusão do curso, este variou de 4 anos, que é previsto, a 6 anos, conforme quadro a seguir.

QUADRO 3 - TEMPO GASTO PELO ALUNO ANGOLANO PARA CONCLUSÃO DO CURSO DE GRADUAÇÃO EM ENFERMAGEM

\begin{tabular}{|c|c|c|c|}
\hline $\begin{array}{c}\text { Duração do curso } \\
\text { em anos }\end{array}$ & $\begin{array}{c}\text { Número de alunos } \\
\text { que concluíram }\end{array}$ & $\begin{array}{c}\text { Número de alunos } \\
\text { com previsão de } \\
\text { conclusão }\end{array}$ & Total \\
\hline 4 & 9 & 4 & 13 \\
5 & 2 & 2 & 4 \\
6 & 1 & - & 1 \\
\hline Total & 12 & $\mathbf{6}$ & $\mathbf{1 8}$ \\
\hline
\end{tabular}

Atualmente encontram-se matriculados nesta unidade 6 alunos com expectativa de que 4 concluirão o curso em 4 e 2 em 5 anos. Informamos que o término do convênio desta Escola firmado com o MINSA está previsto para o 
final de 1996, ocasião em que os alunos que ingressaram em 1993 concluirão o curso de graduação.

Cabe ainda esclarecer que 3 alunos desistiram do curso, voltando para seu país de origem. Os motivos foram reprovações em disciplinas dos primeiros, semestres do curso e conseqüentemente, a suspensão da bolsa.

No que diz respeito ao desempenho acadêmico do estudante angolano, constatamos que os alunos das duas primeiras turmas (88 e 89) não tiveram um rendimento satisfatório, nos primeiros semestres do curso (área básica), ficando laquém da média da classe com várias reprovações. Entretanto gostaríamos de tecer algumas considerações sobre tal fato.

Sabemos que a mudança para um país estrangeiro requer um período de adaptação, mesmo que nele se fale a mesma língua do país de origem. Por outro lado, o ingresso na universidade também requer um período de adaptação ao ambiente escolar, e ao contexto acadêmico através do entrosamento com colegas, professores, disciplinas.

Para tais alunos, este período foi bastante conturbado, pois chegaram à Escola semanas após o início do ano letivo, inteirando-se da matéria já ministrada, ao mesmo tempo que conheciam os colegas, professores, a cidade e a cultura do novo país.

Acreditamos que tais fatos contribuíram para que o desempenho acadêmico destes alunos tenha sido insatisfatório. Lembramos ainda, que no critério de seleção destas duas turmas prevaleceu o aspecto político partidário, o que pode também ter colaborado para que tal desempenho acadêmico tenha ocorrido.

Através das médias semestrais dos estudantes que ingressaram a partir de 1990, verificamos que não houve diferença significativa em relação aos demais alunos, sendo que alguns obtiveram as maiores médias da classe no semestre.

Enfatizamos que houve mudança nos critérios de seleção, no período de chegada e ainda puderam contar com a recepção dos colegas dos anos anteriores, além da atuação do "grupo de apoio às atividades acadêmica, financeira e social", constituído por docentes e funcionários desta Unidade.

Outro aspecto a considerar é quanto à integração dos estudantes convênio com os demais alunos no decorrer do curso. Pudemos perceber que em relação às primeiras turmas houve receptividade por parte da classe e empenho em ajudá-los na recuperação das aulas perdidas e até mesmo tentando protegê-los das dificuldades inerentes à adaptação em geral.

Quanto às turmas posteriores, como os alunos chegaram no mesmo período, percebemos que a integração ocorreu naturalmente. No decorrer do curso constatamos que alguns deles se destacaram tomando-se líderes da classe. 
Como foi mencionado anteriormente, este convênio tinha por objetivo não só formar enfermeiros, como também prepará-los para assumirem funções de docência e de gerenciamento de unidade de ensino em seu país.

Para o cumprimento desta cláusula a Escola de Enfermagem de Ribeirão Preto -USP desenvolveu várias atividades que passaremos a relatar.

Através da Comissão de Graduação foi promovido um curso de extensão universitária intitulado: "A Escola de Enfermagem de Ribeirão Preto: estrutura e funcionamento didático-administrativo", com carga horária de 77 horas, com o propósito de fornecer informações e experiências que pudessem contribuir para o exercício das atividades didático-administrativas que os futuros enfermeiros deveriam exercer em escolas de enfermagem do seu país. Este curso contou com uma programação teórica e estágio prático em cada setor administrativo e acadêmico desta Unidade.

Visando a integração destes alunos nas questões didático-administrativo da Universidade, propiciou-se a participação como ouvintes em algumas comissões, tais como: de Laboratório, de Informática, de Assessoria para Intercâmbio Nacional e Internacional, do Centro de Vivência, e ainda do acompanhamento das atividades técnico-administrativas da Biblioteca Central do Campus de Ribeirão Preto e da sala de leitura "Glete de Alcântara" da Escola de Enfermagem de Ribeirão Preto. Acreditamos que tais atividades possibilitaram ao aluno vivenciar situações administrativas que poderão subsidiar seu futuro desempenho profissional.

Houve ainda a solicitação por parte do MINSA que a EERP-USP oferecesse cursos específicos sobre Gestão de Instituição de Ensino, Gestão e Administração de Recursos Humanos e Gestão Financeira. Embora sendo assuntos de grande importância para a enfermagem e abordados na disciplina de Administração Aplicada à Enfermagem Hospitalar, houve necessidade de elaborar cursos específicos contando com especialistas nos assuntos. Como Angola não repassou verba para os referidos cursos, estes não se efetivaram.

Embora desde o início do convênio, o estudante angolano tenha sido tutelado pela Comissão de Graduação no que diz respeito ao desempenho acadêmico, com a criação do "grupo de apoio às atividades acadêmica, financeira e social" foi estabelecido um "programa de acompanhamento sistemático".

Este programa constava de encontros quinzenais com cada aluno, visando avaliá-lo e orientá-lo nas disciplinas em curso, nas atividades extracurriculares realizadas e no planejamento de novas atividades. Era solicitado a ele que fizesse também uma auto-avaliação de seu desempenho. 
Estes dados nos davam condições de ajudá-lo nas dificuldades apresentadas buscando alternativas para resolução dos problemas, respeitando suas especificidades. Por outro lado, procurávamos estimulá-lo a buscar novas experiências se engajando em áreas de maior afinidade para o aprofundamento de conteúdos, participando também de cursos extracurriculares, encontros, seminários e congressos, tanto específicos da profissão como em outras áreas mais abrangentes.

No tocante a este aspecto é importante informar que houve maior interesse nas áreas de Enfermagem Matemo-Infantil, Enfermagem de Saúde Pública e Administração Aplicada à Enfermagem; entendemos que estas seriam as áreas de prioridade em que futuramente deverão atuar.

Para melhor desenvolvimento destas atividades, estes dados eram registrados numa ficha específica (em anexo). No início de cada semestre letivo ou ainda em situações emergências (atraso de bolsas, visita da delegação de Angola) era feito grupo de discussão com todos os alunos angolanos.

Este programa foi desenvolvido pela Presidente da Comissão de Graduação e a Coordenadora do $1^{\circ}$ ano enquanto membros do "Grupo de Apoio às atividades acadêmica, financeira e social do aluno convênio".

Para atender as exigências da formação do aluno com o grau de Licenciado e não tendo ainda a EERP-USP, naquele momento a aprovação do seu Curso de Licenciatura, 7 alunos matricularam-se no Curso de Licenciatura em Enfermagem na UNESP - Araraquara. Estes alunos mantiveram durante este período vínculo com a Escola, através de orientação e acompanhamento de atividades no ano de 1994 dois desses concluíram a licenciatura em enfermagem na EERP-USP.

No período de 1989 a 1995 a EERP-USP recebeu a visita de 7 delegações de membros representantes do Ministério da Saúde de Angola, pertencentes ao Departamento de Formação Técnico Profissional, Instituto Superior de Enfermagem e Setor de Bolsas de Estudo da Seção de Recursos Humanos.

Estas delegações se reuniram com a Direção da EERP-USP, a Comissão de Graduação e Comissão de Cultura e Extensão Universitária, com objetivo de avaliar o programa e o desempenho acadêmico dos alunos, rever alguns termos do acordo e ajudar os bolsistas nos aspectos relativos à manutenção e sistematização das bolsas de estudo.

Em dezembro de 1991, a delegação do Ministério da Saúde, participou da solenidade de colação de grau da primeira turma de alunos angolanos formados pela EERP-USP. Nos anos subseqüentes, a República Popular de Angola foi representada pelo Adido Cultural nas cerimônias de colação de grau dos demais alunos. Na última reunião que ocorreu em junho de 1995, recebemos a visita de uma ex-aluna graduanda em 1992, como membro de delegação representando o Departamento de Formação Técnica Profissional de Angola. 
Solicitamos aos alunos angolanos que listassem as facilidades e dificuldades que vivenciaram neste período de formação em um país estrangeiro.

As dificuldades relatadas foram:

- em relação à moradia -alugar casas por falta de fiador;

- adaptação ao país;

- atraso nas bolsas que chegou a ser até de 6 meses;

- corte imediato da bolsa devido a reprovação em disciplinas pré-requisitos sem consideração das dificuldades circunstanciais;

- atraso no envio de passagens para o regresso dos alunos ao país de origem.

Os estudantes citaram ainda que o desempenho do "grupo de apoio às atividades acadêmica, financeira e social" foi importante na solução das dificuldades.

\section{CONSIDERAÇÕES}

Enquanto redigíamos este "paper" alguns pontos para reflexão surgiram:

Em primeiro lugar a satisfação em estar colaborando no desenvolvimento de um país irmão e no desenvolvimento da própria profissão de Enfermagem, pois os exalunos que estão retornando ao país de origem já começam a ocupar cargos importantes na formação de novos profissionais de enfermagem.

As primeiras turmas foram as que provavelmente mais tiveram dificuldades na adaptação. Como já foi mencionado, chegaram após o início do ano letivo, causando transtorno para a unidade, que precisou buscar alternativas para repor conteúdo das aulas já ministradas.

Por outro lado, o órgão financiador (ASDI) exigia a conclusão do curso em 4 anos, ou seja, não aceitando o período de adaptação do aluno estrangeiro, previsto pelos demais órgãos financiadores. Tal exigência acarretava muita ansiedade tanto aos alunos como professores.

Outro aspecto a ser ressaltado é quanto a morosidade por parte de Angola nas comunicações de decisões dos processos acadêmicos e manutenção de bolsas refletindo no desempenho do aluno. Este fato talvez fosse conseqüência das constantes mudanças que ocorriam nos órgãos administrativos e políticos daquele país.

A formação do profissional inclui não só o conhecimento adquirido nos estudos formais, mas também através da troca de experiências e convívio com estudantes, professores e funcionários. Verificamos que com a presença de alunos angolanos estas trocas ficaram mais acentuadas. Houve ainda períodos de muito sofrimento, mas também de solidariedade em situações difíceis para todos como atraso nas bolsas, acidentes automobilísticos, doenças, cirurgias e o desenrolar dos acontecimentos políticos em Angola. 
Enfim, o intercâmbio com alunos de outros países tem sido fator de crescimento para a EERP.

\section{FONTES CONSULTADAS}

- Documentação Técnica da Seção de Graduação (prontuário dos alunos, atas das reuniões da C.B. e relatórios técnicos)

- Termos de acordo e convênio

\section{FICHA DE ORIENTAÇÃO}

Aluno:

Ano:

Semestre:

Dia:

Horário:

DISCIPLINAS

\begin{tabular}{|l|l|l|}
\hline NOME & AVALIAÇÃO & FREQÜÊNCIA \\
& & \\
\hline
\end{tabular}

AUTO-AVALIAÇÃO

ATIVIDADES EXTRACURRICULARES REALIZADAS:

EVENTOS:

PERÍODO:

OUTROS:

ATIVIDADES EXTRACURRICULARES PLANEJADAS PARA O SEMESTRE SEGUINTE: 